Braz J Med Biol Res, January 2012, Volume 45(1) 20-24

doi: 10.1590/S0100-879X2011007500156

Correlation between total nitrite/nitrate concentrations and monoamine oxidase (types A and B) and semicarbazide-sensitive amine oxidase enzymatic activities in human mesenteric arteries from non-diabetic and type 2 diabetic patients

S.F. Nunes, I.V. Figueiredo, J.S. Pereira, M.C. Lopes and M.M. Caramona

The Brazilian Journal of Medical and Biological Research is partially financed by
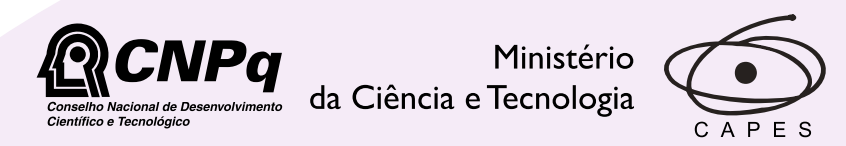

Ministério da Educação

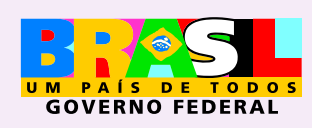

Institutional Sponsors
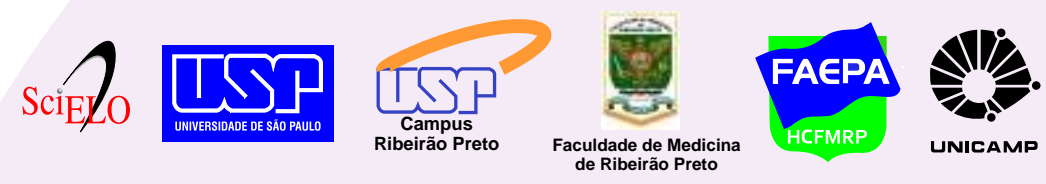

$\oplus$ SHIMADZU

UNICAMP
AFP

Associaçäo
Fundo
delncentivo de Incentivo
à Pesquisa

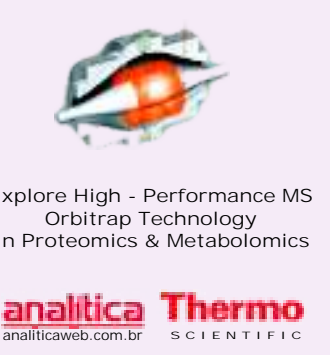

analitica Thermo 


\title{
Correlation between total nitrite/nitrate concentrations and monoamine oxidase (types $A$ and $B$ ) and semicarbazide-sensitive amine oxidase enzymatic activities in human mesenteric arteries from non-diabetic and type 2 diabetic patients
}

\author{
S.F. Nunes ${ }^{1}$, I.V. Figueiredo ${ }^{1}$, J.S. Pereira ${ }^{2}$, M.C. Lopes ${ }^{1}$ and M.M. Caramona ${ }^{1}$ \\ ${ }^{1}$ Laboratório de Farmacologia, Faculdade de Farmácia, Universidade de Coimbra, Coimbra, Portugal \\ 2Instituto Português de Oncologia de Coimbra, Coimbra, Portugal
}

\begin{abstract}
The aim of this study was to determine the correlation between total nitrite/nitrate concentrations (NOx) and the kinetic parameters of monoamine oxidase enzymes (MAO-A and MAO-B) and semicarbazide-sensitive amine oxidase (SSAO) in human mesenteric arteries. Arteries were from non-diabetic and type 2 diabetic patients with sigmoid or rectum carcinoma for whom surgery was the first option and who were not exposed to neo-adjuvant therapy. Segments of human inferior mesenteric arteries from non-diabetic ( $61.1 \pm 8.9$ years old, 7 males and 5 females, $N=12)$ and type 2 diabetic patients $(65.8 \pm 6.2$ years old, 8 males and 4 females, $\mathrm{N}=12$ ) were used to determine NOx concentrations and the kinetic parameters of MAO-A, MAO-B and SSAO by the Griess reaction and by radiochemical assay, respectively. The NOx concentrations in arteries from diabetic patients did not differ significantly from those of the non-diabetic group $(10.28 \pm 4.61 \mathrm{vs} 10.71 \pm 4.32 \mathrm{nmol} / \mathrm{mg}$ protein, respectively). In the non-diabetic group, there was a positive correlation between NOx concentrations and MAO-B parameters: $K_{m}(r=0.612, P=$ $0.034)$ and $V_{\max }(r=0.593, P=0.042)$, and a negative correlation with the SSAO parameters: $K_{m}(r=-0.625, P=0.029)$ and $V_{\max }(r=-0.754, P=0.005)$. However, in the diabetic group no correlation was found between NOx concentrations and the three kinetic parameters of the enzymes. These results suggest an important function of sympathetic nerves and vascular NOx concentrations in arteries of non-diabetic patients. Thus, these results confirm the importance of a balance between oxidants and antioxidants in the maintenance of vascular homeostasis to prevent oxidative stress.
\end{abstract}

Key words: Nitric oxide; Monoamine oxidase; Semicarbazide-sensitive amine oxidase; Mesenteric arteries; Type 2 diabetes

\section{Introduction}

Increased concentrations of reactive oxygen species (ROS) have been implicated in vascular diseases as well as diabetic vascular complications. Molecular oxygen, under electron reduction, forms superoxide anion $\left(\mathrm{O}_{2}^{-}\right)$, which serves as a progenitor for hydrogen peroxide $\left(\mathrm{H}_{2} \mathrm{O}_{2}\right)$ and reduces bioactive nitric oxide (NO), leading to endothelial dysfunction (1). Also, the oxidation of biogenic amines by monoamine oxidase (MAO, types $\mathrm{A}$ and $\mathrm{B}$ ) and semicarbazide-sensitive amine oxidase (SSAO) results in the production of the corresponding aldehyde, $\mathrm{H}_{2} \mathrm{O}_{2}$ and ammonia $(2,3)$. The degradation of $\mathrm{H}_{2} \mathrm{O}_{2}$ is rapidly metabolized by the Fenton reaction to the reactive hydroxyl radical and this leads to the onset and/or progression of cellular oxidative injury (4).

$\mathrm{O}_{2}$ - rapidly scavenges $\mathrm{NO}$ synthesized from L-arginine by nitric oxide synthase (NOS) to form peroxynitrite (ONOO-), which is a strong oxidant that can oxidize tetrahydrobiopterin $\left(\mathrm{BH}_{4}\right)$, an important co-factor for NOS activity. Decreased $\mathrm{BH}_{4}$ concentrations alter the activity of endothelial NOS (eNOS) in blood vessels, cause enhanced uncoupling of eNOS, increase $\mathrm{O}_{2}$ - production and decrease $\mathrm{NO}$ in blood vessels, thus favoring production of $\mathrm{ONOO}^{-}$(5). Another isoform with a relevant role is inducible NOS (iNOS), which is expressed in macrophages and other tissues (6). In ad-

Correspondence: M.M. Caramona, Laboratorório de Farmacologia, Faculdade de Farmácia, Universidade de Coimbra, 3000-548 Coimbra, Portugal. Fax: +351-239-488-503. E-mail: caramona@ci.uc.pt

Received April 11, 2011. Accepted November 4, 2011. Available online November 25, 2011. Published January 16, 2012. 
dition to eNOS and iNOS, mitochondrial NOS (mtNOS), localized in the inner mitochondrial membrane, modulates respiratory rate and ATP synthesis (7).

The MAO enzyme is a flavoprotein associated with the outer membrane of mitochondria. There are two isoforms, MAO-A and MAO-B, distributed throughout the body, which are responsible for oxidative deamination of biogenic amines. Dopamine, tyramine and tryptamine are substrates for both isoforms, but MAO-A preferentially metabolizes noradrenaline and 5-hydroxytryptamine, whereas MAO-B preferentially metabolizes phenylethylamine (2).

The SSAO enzyme contains copper as a co-factor and is distributed in the plasma membrane of various tissues, present mainly in blood vessels, fibroblasts, adipocytes, and placenta. The SSAO enzyme metabolizes not only primary biogenic amines such as methylamine and aminoacetone, but also histamine, tyramine and dopamine. SSAO is also known as vascular adhesion protein-1 (VAP-1) and has been identified as one of the adhesion molecules involved in the leukocyte extravasation process (3).

There is evidence suggesting the involvement of MAO in neurodegenerative diseases, as well as an association between MAO and NO in the central nervous system (8). However, NO interference with MAO-A, MAO-B and SSAO kinetic parameters in peripheral arteries is poorly understood. Therefore, the aim of the present investigation was to study the correlation between total nitrite and nitrate (NOx) concentrations and the kinetic parameters of these enzymes in homogenates of human inferior mesenteric arteries obtained from non-diabetic and type 2 diabetic patients to better understand the mechanism of diabetes, a disease that affects many people.

\section{Patients and Methods}

The human tissues were obtained at the Portuguese Oncology Institute of Coimbra from March 2008 to February 2009. The study was approved by the Institute's Medical Ethics Committee and all participants gave written informed consent. Only non-smoking patients participated in the study and none of the participants suffered from thyroid dysfunction, renal or liver disorders.

Segments of human inferior mesenteric arteries from 12 non-diabetic patients $(61.1 \pm 8.9$ years old, 7 males and 5 females) and 12 type 2 diabetic patients $(65.8 \pm 6.2$ years old, 8 males and 4 females) were obtained from individuals admitted for surgery. Both diabetic and non-diabetic patients in this study had sigmoid or rectum carcinoma and had not been subjected to neo-adjuvant therapeutics and whose primary option was surgery. The non-diabetic patients were selected according to the following criteria: blood glucose concentrations $<110 \mathrm{mg} / \mathrm{dL}$, and absence of hypertension or renal disease (serum creatinine $<1.20$ $\mathrm{mg} / \mathrm{dL}$ ). The patients with type 2 diabetes were selected according to the following criteria: blood glucose concen- trations $>110 \mathrm{mg} / \mathrm{dL}, \mathrm{HbA}_{1 \mathrm{c}}>6 \%$ and on treatment with an oral antidiabetic drug.

To avoid the effects of pathological anatomy, vessels of greatest caliber were selected, namely the inferior mesenteric artery, and only macroscopically healthy vessels were used. The arteries were placed in cold physiological saline solution and immediately transported to the laboratory where $\pm 200 \mathrm{mg}$ of each artery was homogenized in $10 \mathrm{mM}$ sodium phosphate buffer, $\mathrm{pH} 7.4$, at $4^{\circ} \mathrm{C}$ and the supernatant was obtained and stored at $-80^{\circ} \mathrm{C}$ until further use.

The tissue homogenates were used for the measurement of NOx concentrations by the Griess reaction (9), using $1 \mathrm{~g} / \mathrm{L}$ sulfanilamide from Sigma-Aldrich (USA), 25 $\mathrm{g} / \mathrm{L}$ ortho-phosphoric acid from Merck (Germany), and 0.1 g/L N(-1-naphthyl) ethylenediamine from Sigma-Aldrich, as reagents. Nitrate concentration was measured as nitrite after enzymatic conversion by nitrate reductase from Aspergillus spp, and nitrite concentration was measured after deproteinization with zinc sulfate $(300 \mathrm{~g} / \mathrm{L})$ at a 1:20 ratio $(\mathrm{v} / \mathrm{v})$ in order to obtain a final concentration of $15 \mathrm{~g} / \mathrm{L}$. The NOx values represent the sum of the nitrite and nitrate concentrations.

MAO-A, MAO-B and SSAO were determined by radiochemical methods using ${ }^{3} \mathrm{H}-5$-hydroxytryptamine creatinine sulfate $\left({ }^{3} \mathrm{H}-5-\mathrm{HT}\right)$ in the concentration range from 50 to $1000 \mu \mathrm{M}$ as a specific substrate for MAO-A, 5 to 160 $\mu \mathrm{M}{ }^{14} \mathrm{C}-\beta$-phenylethylamine hydrochloride $\left({ }^{14} \mathrm{C}-\beta-\mathrm{PEA}\right)$ as a specific substrate for MAO-B, and ${ }^{14} \mathrm{C}$-benzylamine $\left({ }^{14} \mathrm{C}-\mathrm{BZ}\right)$ in the concentration range from 50 to $1600 \mu \mathrm{M}$ as a specific substrate for SSAO. For selective MAO-A and MAO-B inhibition, $0.1 \mathrm{mM}$ selegiline was used as an MAO-B inhibitor and 1.0 $\mu \mathrm{M}$ clorgyline as an MAO-A inhibitor (10). All other reagents used were of analytical grade. The radioactivity released from the mixtures was measured with a Packard 2000 Tri-Carb liquid scintillation counter (Australia) and data were calculated in order to report the MAO-A, MAO-B and SSAO activities as nanomoles of substrate metabolized per mg protein per incubation hour (nmol-mg protein $\left.{ }^{-1} \cdot \mathrm{h}^{-1}\right)$.

The results are reported as means \pm SD. Statistical comparison of the groups was performed by the nonparametric Mann-Whitney test, and Pearson's correlation was used to test the correlations under study. The statistics were performed using the commercial GraphPad Prism software version 4.0 (USA), with the level of significance set at $\mathrm{P}<0.05$.

\section{Results}

In this study, no significant difference was found between the type 2 diabetic group and the non-diabetic group regarding the levels of nitrites $(3.57 \pm 2.58$ vs $4.47 \pm 2.17 \mathrm{nmol} /$ mg protein, respectively) and nitrates (6.71 \pm 3.33 vs 6.24 $\pm 3.44 \mathrm{nmol} / \mathrm{mg}$ protein, respectively) in homogenates of inferior mesenteric arteries. The mean NOx concentrations 
found in type 2 diabetic patients did not differ from that of non-diabetic patients $(10.28 \pm 4.61$ vs $10.71 \pm 4.32$ $\mathrm{nmol} / \mathrm{mg}$ protein, respectively).

Table 1 shows the kinetic parameters of type 2 diabetic patients and controls. No significant difference was found between the two groups in $K_{m}$ values for the three enzymes. There were differences in MAO-A and SSAO ( $\left.V_{\text {max }}\right)$ between the diabetic and non-diabetic groups but no significant difference for MAO-B ( $\left.V_{\max }\right)$ between groups.

In type 2 diabetic patients, there was no correlation between NOx concentrations and the kinetic parameters of the three enzymes. No significant correlation was found between NOx concentrations and MAO-A $\left(K_{\mathrm{m}}\right.$ and $\left.V_{\max }\right)$ in the non-diabetic patients. However, a positive correlation was obtained between NOx concentrations and MAO-B regarding $K_{\mathrm{m}}$ (Pearson $r$ $=0.612, \mathrm{P}=0.034)$ and $V_{\max }($ Pearson $r=0.593, \mathrm{P}=$ $0.042)$. In contrast, there was a negative correlation between NOx concentrations and SSAO regarding
Table 1. Kinetic parameters of MAO-A, MAO-B and SSAO $\left(V_{\max }\right.$ and $\left.K_{\mathrm{m}}\right)$ in mesenteric artery homogenates from patients with type 2 diabetes and from non-diabetic patients.

\begin{tabular}{|c|c|c|}
\hline & $\begin{array}{c}\text { Type } 2 \text { diabetic } \\
\text { patients }(\mathrm{N}=12)\end{array}$ & $\begin{array}{c}\text { Non-diabetic } \\
\text { patients }(\mathrm{N}=12)\end{array}$ \\
\hline \multicolumn{3}{|l|}{ MAO-A } \\
\hline$V_{\max }\left(\mathrm{nmol} \cdot \mathrm{mg}\right.$ protein $\left.{ }^{-1} \cdot \mathrm{h}^{-1}\right)$ & $29.86 \pm 11.74$ & $60.06 \pm 21.43^{*}$ \\
\hline$K_{\mathrm{m}}(\mu \mathrm{M})$ & $259.50 \pm 101.80$ & $178.30 \pm 99.17$ \\
\hline \multicolumn{3}{|l|}{ MAO-B } \\
\hline$V_{\max }\left(\mathrm{nmol} \cdot \mathrm{mg}\right.$ protein $\left.{ }^{-1} \cdot \mathrm{h}^{-1}\right)$ & $14.69 \pm 7.37$ & $15.20 \pm 3.03$ \\
\hline$K_{\mathrm{m}}(\mu \mathrm{M})$ & $86.63 \pm 52.66$ & $100.50 \pm 38.87$ \\
\hline \multicolumn{3}{|l|}{ SSAO } \\
\hline$V_{\max }\left(\mathrm{nmol} \cdot \mathrm{mg}\right.$ protein $\left.{ }^{-1} \cdot \mathrm{h}^{-1}\right)$ & $143.70 \pm 62.41$ & $229.10 \pm 46.28^{*}$ \\
\hline$K_{\mathrm{m}}(\mu \mathrm{M})$ & $225.20 \pm 167.10$ & $301.00 \pm 127.30$ \\
\hline
\end{tabular}

Data are reported as means $\pm S D$. MAO-A = monoamine oxidase type $\mathrm{A}$; $\mathrm{MAO}-\mathrm{B}=$ monoamine oxidase type $\mathrm{B}$; SSAO = semicarbazide-sensitive amine oxidase. ${ }^{*} \mathrm{P}<0.05$ compared to diabetic patients (MannWhitney test).

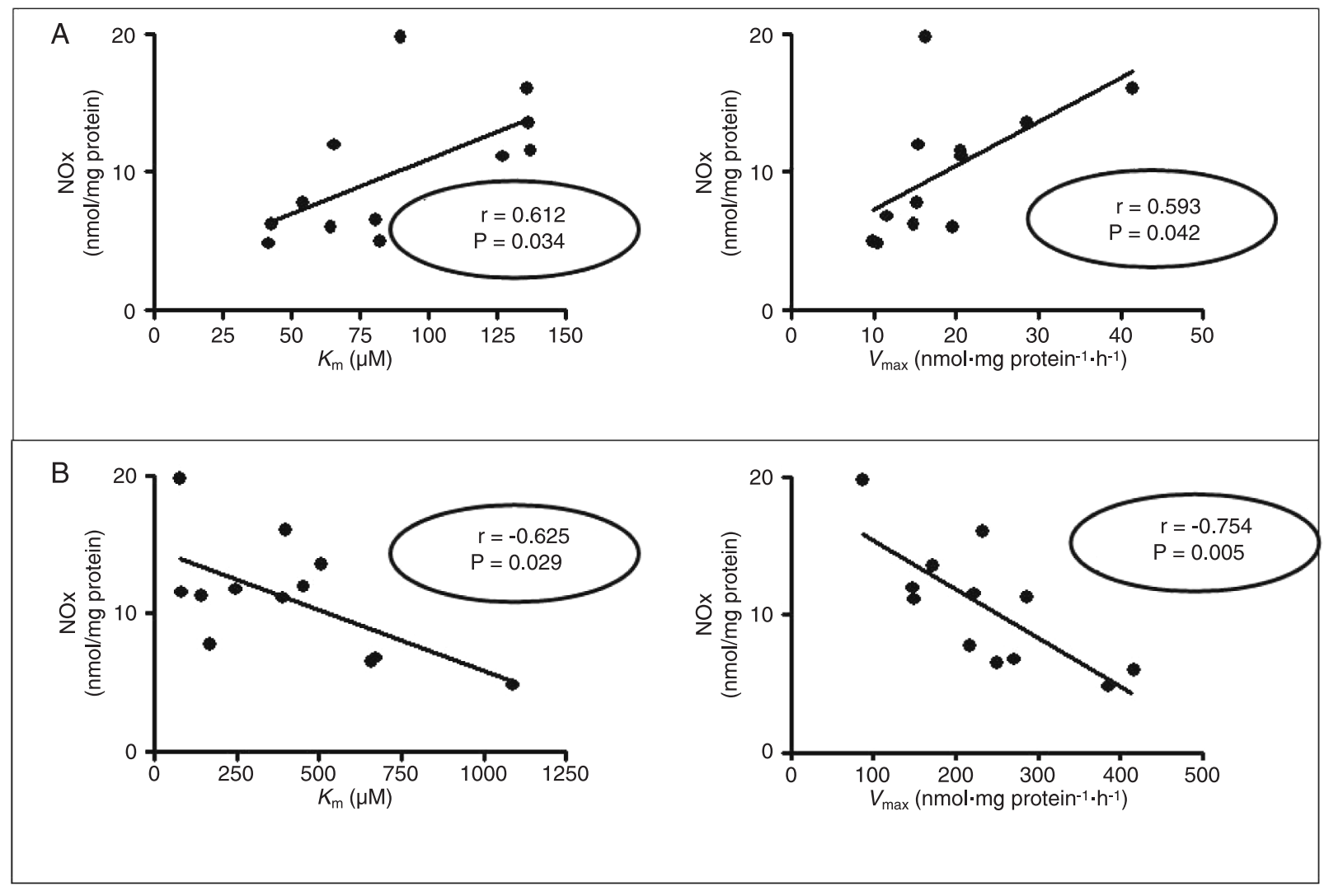

Figure 1. Scatter diagrams showing the correlation between NOx concentrations ( $y$-axis) and $K_{m}$ or $V_{\max }(x-a x i s)$ of MAO-B (A) and SSAO (B) in mesenteric arteries of the control group $(N=12)$ determined by the Pearson method. NOx = total nitrite/nitrate concentrations; $\mathrm{MAO}-\mathrm{B}=$ monoamine oxidase type $\mathrm{B}$ : SSAO = semicarbazide-sensitive amine oxidase. 
$K_{\mathrm{m}}($ Pearson $r=-0.625, P=0.029)$ and $V_{\max }($ Pearson $r=$ $-0.754, \mathrm{P}=0.005$; Figure 1).

\section{Discussion}

In this study, we found: 1) no significant difference for NOx concentrations in the artery homogenates between the type 2 diabetic and non-diabetic groups; 2 ) in the diabetic group, NOx concentrations did not correlate with MAO-A, MAO-B or SSAO enzyme activities; 3 ) in the non-diabetic group, NOx did not correlate with MAO-A kinetic parameters $\left(K_{\mathrm{m}}\right.$ and $\left.V_{\max }\right)$, but NOx was positively correlated with MAO-B kinetic parameters $\left(K_{\mathrm{m}}\right.$ and $\left.V_{\max }\right)$ and negatively correlated with SSAO kinetic parameters $\left(K_{\mathrm{m}}\right.$ and $\left.V_{\max }\right)$. This novel contribution may be useful to better understand the importance of NOx concentrations and biogenic amines in human vessels under physiological and pathophysiological conditions.

Endothelial cell dysfunction can release large amounts of ROS, including $\mathrm{O}_{2}^{-}, \mathrm{H}_{2} \mathrm{O}_{2}$ and $\mathrm{NO}$, that promote abnormal vascular growth, such as atherosclerosis in patients with diabetes mellitus (11). The ROS generated in physiological processes are closely regulated by enzymes such as NOS and nicotinamide adenine dinucleotide oxidase (1).

Oxidative stress is defined as an imbalanced redox state in which pro-oxidants overwhelm antioxidant capacity, resulting in increased ROS production, which plays a role in injury to cellular structures, including lipids, proteins and nucleic acids, as well as in the pathogenesis of various diseases such as cancer, diabetes, atherosclerosis, neurodegenerative diseases, and aging $(4,6)$.

Recent evidence indicates that the cytotoxic effect of $\mathrm{NO}$ is due to ONOO-, which is produced by the reaction between $\mathrm{NO}$ and $\mathrm{O}_{2}^{-}$. ONOO- interacts with lipids, DNA and proteins via direct or indirect oxidative reactions. These reactions produce modulations of cell signaling and induce cellular necrosis or apoptosis (12).

The innervation and NOS inhibition effects have been studied in the mesenteric arteries of the golden hamster using immunohistochemical and pharmacological methods, showing that the peripheral sympathetic nerves and NO regulate the functions of mesenteric arteries (13). In our study, we did not detect differences in NOx concentrations in mesenteric artery homogenates between the diabetic and non-diabetic groups. These findings suggest that a compensatory response to prolonged oxidative stress occurs, that the $\mathrm{NO}$ in the arteries is still sufficient and that the

\section{References}

1. Cai $\mathrm{H}$. Hydrogen peroxide regulation of endothelial function: origins, mechanisms, and consequences. Cardiovasc Res 2005; 68: 26-36.

2. Billett EE. Monoamine oxidase (MAO) in human peripheral disease probably does not occur until these compensatory mechanisms fail (5). Indeed, a recent study from our group has indicated an increase in NOx concentrations in the serum of type 2 diabetic patients (14).

The direct interaction between the effects of $\mathrm{NO}$ on MAO activity in rat liver suggests that the generation of NO catalyzed by mtNOS is involved in the regulation of various mitochondrial functions (15). This enzyme may provide the basis for the regulation of cellular energy metabolism, oxygen consumption and ROS production. However, it is not possible to determine the NO synthesized by mtNOS using the Griess method (5).

It is known that in the gastrointestinal tract, the circulatory system and the liver, MAO-A and MAO-B regulate the deamination of amines from the diet, which exerts a potent vasopressor effect (16). However, the physiological relevance of SSAO in the gastrointestinal tract and blood vessels remains unclear. Biochemically, SSAO converts primary amines into potentially cytotoxic metabolites (17). The lack of correlation between NOx and SSAO kinetic parameters in the arteries of diabetic patients suggests that the damage to blood vessels can cause release of the SSAO protein into the circulation, as previously reported by our group $(14,18)$. Therefore, serum SSAO activity may be a useful biochemical marker for the control of vascular complications in diabetic patients (17-19).

The lack of correlation between the enzyme activities of MAO-A, MAO-B and SSAO with NOx concentrations in mesenteric arteries of diabetic patients and the correlation between MAO-B and SSAO with NOx concentrations in non-diabetic patients may be explained by the fact that NO down-regulates the expression of the Fenton reaction to prevent catalytic pro-oxidant reactions (20).

These results show that MAO-B and SSAO kinetic parameters are statistically correlated with $\mathrm{NOx}$ concentration in the inferior mesenteric arteries of non-diabetic patients, but these correlations were not observed in the arteries of diabetic patients, suggesting possible changes in vascular function in these arteries. This possibility must be further explored, namely by immunohistochemical analysis or by the study of other oxidative stress biomarkers.

\section{Acknowledgments}

Research supported by the Portuguese Foundation for Science and Technology (FCT: SFRH/BD/23606/2005), and the Center for Pharmaceutical Studies (CEF). 
2003; 1647: 48-54.

4. Valko M, Leibfritz D, Moncol J, Cronin MT, Mazur M, Telser $\mathrm{J}$. Free radicals and antioxidants in normal physiological functions and human disease. Int J Biochem Cell Biol 2007; 39: 44-84.

5. Mueller CF, Laude K, McNally JS, Harrison DG. ATVB in focus: redox mechanisms in blood vessels. Arterioscler Thromb Vasc Biol 2005; 25: 274-278.

6. Moncada S, Higgs EA. Nitric oxide and the vascular endothelium. Handb Exp Pharmacol 2006; 213-254.

7. Giulivi C. Functional implications of nitric oxide produced by mitochondria in mitochondrial metabolism. Biochem $\mathrm{J} 1998$; 332 (Part 3): 673-679.

8. Girgin SF, Sozmen EY, Ersoz B, Mentes G. Link between monoamine oxidase and nitric oxide. Neurotoxicology 2004; 25: 91-99.

9. Moshage $H$, Kok B, Huizenga JR, Jansen PL. Nitrite and nitrate determinations in plasma: a critical evaluation. Clin Chem 1995; 41: 892-896.

10. Figueiredo IV, Martinez CA, Cotrim MD, Caramona MM, Callingham BA. Monoamine oxidase activities in human cystic and colonic arteries - influence of age. J Neural Transm Suppl 1998; 52: 217-223.

11. Nakagami $H$, Kaneda $Y$, Ogihara $T$, Morishita R. Endothelial dysfunction in hyperglycemia as a trigger of atherosclerosis. Curr Diabetes Rev 2005; 1: 59-63.

12. Pacher P, Beckman JS, Liaudet L. Nitric oxide and peroxynitrite in health and disease. Physiol Rev 2007; 87: 315-424.

13. Hill B, Ralevic V, Crowe R, Burnstock G. Innervation and nitric oxide modulation of mesenteric arteries of the golden hamster. Eur J Pharmacol 1996; 317: 275-283.

14. Nunes SF, Figueiredo IV, Soares PJ, Costa NE, Lopes MC, Caramona MM. Semicarbazide-sensitive amine oxidase activity and total nitrite and nitrate concentrations in serum: novel biochemical markers for type 2 diabetes? Acta Diabetol 2009; 46: 135-140.

15. Muriel P, Perez-Rojas JM. Nitric oxide inhibits mitochondrial monoamine oxidase activity and decreases outer mitochondria membrane fluidity. Comp Biochem Physiol C Toxicol Pharmacol 2003; 136: 191-197.

16. Herraiz T, Chaparro C. Analysis of monoamine oxidase enzymatic activity by reversed-phase high performance liquid chromatography and inhibition by beta-carboline alkaloids occurring in foods and plants. J Chromatogr A 2006; 1120: 237-243.

17. Meszaros Z, Szombathy T, Raimondi L, Karadi I, Romics L, Magyar K. Elevated serum semicarbazide-sensitive amine oxidase activity in non-insulin-dependent diabetes mellitus: correlation with body mass index and serum triglyceride. Metabolism 1999; 48: 113-117.

18. Nunes SF, Figueiredo IV, Pereira JS, Soares PJ, Caramona MM, Callingham B. Changes in the activities of semicarbazide-sensitive amine oxidase in inferior mesenteric artery segments and in serum of patients with type 2 diabetes. Acta Diabetol 2010; 47: 179-182.

19. Magyar K, Mészáros Z, Mátyus P. Semicarbazide-sensitive amine oxidase. Its physiological significance. Pure Appl Chem 2001; 73: 1393-1400.

20. Lu C, Koppenol WH. Inhibition of the Fenton reaction by nitrogen monoxide. J Biol Inorg Chem 2005; 10: 732-738. 